\title{
FILOGENIA DE CATTLEYA SEÇÃO CATTLEYA BASEADO EM DADOS DE SEQUÊNCIAS DE DNA.
}

\author{
Carlos Eduardo Santos de Jesusi'; Cássio Van Den Berg ${ }^{2}$ e Polliana Rodrigues ${ }^{3}$ \\ 1.Bolsista PIBIC/CNPq, Graduando em Agronomia, Universidade Estadual de Feira de Santana, e- \\ mail:eduardo_eb_saj@hotmail.com \\ 2.Orientador, Departamento de Ciências Biológicas, Universidade Estadual de Feira de Santana, e-mail:vcassio@gmail.com \\ 3.PPós-doutoranda, Departamento de ciências biológicas, Universidade Estadual de Feira de Santana, e-mail: \\ pollirodrigues@yahoo.com.br
}

\section{PALAVRAS-CHAVE(três): Cattleya, Filogenia, Sequenciamento de DNA, Orchidaceae}

\section{INTRODUÇÃO}

Dentro do presente estudo, o objetivo de análise do gênero Cattleya contem, após englobar espécies anteriormente alocadas em Laelia e Sophronitis, um intrincado sistema de classificação infragenérica (van den Berg 2014). É possível observar em seu sistema relações entre gêneros e seções obtidos em trabalhos anteriores na subtribo Laeliinae, que amostraram extensamente Cattleya, Laelia e Sophronitis (van den Berg et al. 2000; van den Berg et al. 2009), com sequências de ITS nuclear e $t r n L-F$ e matK (plastidiais). Essas filogenias indicaram um grupo, que foi chamado de seção Cattleya, e que inclui a espécie tipo do gênero (Cattleya labiata Lindl.) e outras 16 espécies estreitamente relacionadas. Este grupo contém as espécies mais vistosas, mais importantes economicamente e mais utilizadas para fazer híbridos articificiais (van den Berg 2005).

O maior problema na seção Cattleya é para estabelecer suas relações com o pequeno grupo de espécies com sistema de polinização distinto (espécies de flores pequenas e pouco vistosas, $C$. iricolor Rchb.f. C. luteola Lindl., C. mooreana Withner, Allison \& Guenard), que aparece sendo do grupo irmão em estudos da região nuclear ITS. Há um grupo com morfologia muito similar à seção Cattleya (C. wallisii (Rchb.f.) Rchb.f. C. lueddemanniana Rchb.f. C. lawrenceana Rchb.f) se mostraram como sendo distantemente relacionado, por vezes próximo das espécies transferidas de Laelia (com ITS, van den Berg et al. 2000), ou constituindo um grupo à parte em genomas de plastídeos. O pequeno grupo foi chamado seção Lawrenceanae no trabalho sobre a taxonomia infragenérica de Cattleya (van den Berg 2014). A partir de um estudo feito com as espécies bifoliadas do gênero (subgênero Intermedia) foram selecionadas as regiões com grande potencial para resolver relações filogenéticas entre espécies de Cattleya (Santos 2011). Por essa razão foi proposto no presente artigo sequenciar estas regiões para resolver a filogenia das espécies da seção Cattleya. Onde seriam sequenciada regiões não codificantes plastidiais (espaçadores $\operatorname{trnS}$ - $G$, $r p l 32$ trnL, trnD-T, psbA-trnH, íntron e espaçador trnL-F, íntron rps16, matK e íntrons de trnK) em adição às sequências de ITS já existentes. Além de resolver as questões do posicionamento e delimitação da seção, a partir das relações entre as espécies, poderemos fazer um estudo de datação molecular e estudar os padrões biogeográficos, já que as espécies da seção Cattleya se distribuem sempre em habitats alopátricos em regiões montanhosas do leste do Brasil, Venezuela, Côlombia, Ecuador e Peru. No caso da análise biogeográfica, existe grande interesse em estimar a data em que o grupo dispersou dos Andes para a floresta Atlântica.

\section{METODOLOGIA}

Neste projeto aqui apresentado, foi feito o estudo a nível molecular do grupo unifoliado de Cattleya que foi conduzido através de sequências de DNA. Para análise filogenética foi utilizado um indivíduo de cada espécie, ou mais indivíduos em espécies que apresentam ampla distribuição geográfica ou variedades geográficas. O DNA de todas as espécies encontra-se armazenado em 
Biofreezer a $-85{ }^{\circ} \mathrm{C}$ no Laboratório de Sistemática Molecular de Plantas (LAMOL) da UEFS.

A reestruturação da arvore fillogenética e definição do grupo interno e externo tomou como base resultados dos trabalhos anteriores de filogenia da subtribo Laeliinae (van den Berg et al., 2014, 2000 ,

Para amplificação de regiões nucleares e plastidiais utilizaremos sobretudo os primers de Shaw et al. (2005, 2007) e Scarcelli et al. (2010), seguindo os protocolos originais desses artigos, ou protocolos que já otimizamos em Cattleya em outros trabalhos (van den Berg et al. 2009, Santos 2011). Quando as receitas de PCR originais não foram bem sucedidas, utilizamos o Top Taq Master Mix (Qiagen), já otimizado para amplificações difíceis no nosso laboratório. Os produtos amplificados foram purificados com precipitação por PEG-8000 11\% e etanol (Paithankar \& Prasad 1991), e em seguida sequenciados bidirecionalmente com o kit Big Dye 3.1 (Applied Biosystems) no sequenciador automático ABI3130 XL disponível no laboratório. Os eletroferogramas obtidos serão editados e conferidos manualmente com o programa Pre-Gap 4 e Gap4 do pacote Staden (Staden et al. 2000). A partir das sequências consolidadas obtidas por este processo, construiremos matrizes alinhadas através do software MUSCLE (Edgar 2004), seguidos de correção manual, que serão utilizados para as análises filogenéticas e filogeográficas.

\section{RESULTADOS}

Para a análise da região que foi possível ampliar, aqui apresentada neste estudo, sendo apenas trnL-F, pode-se obter boa amplificação para as 16 espécies e 14 apresentaram um bom sequenciamento, Nas demais regiões, obteve boa amplificação, para aproximadamente $90 \%$ das espécies utilizadas no devido estudo. As restas regiões apresentaram dificuldades de amplificação e as matrizes ficaram incompletas sem possibilidade de inclusão no estudo, dentro do tempo de finalização da bolsa, e requerem tempo adicional de laboratório para conclusão. A árvores é apresentada na Fig. 1.

\section{DISCUSSÃO}

No presente estudo a seção Cattleya, do Clado A(0,86 PP) mostrou-se com probabilidade apenas baixa a moderada. Este fator é provavalmente devido ao número insuficiente de regiões ainda incluída no estudo. Portanto deve ser levado em consideração a necessidade de se incluir as regiões de DNA restantes. Apesar disso, os dados indicam um grupo monofilético compatível com a morfologia e compatível com resultados anteriores sem amostrar o total de espécies (van den Berg et al. 2000 e 2009). A disposição da árvore filogenética do presente estudo, se mostrou relativamente congruente apenas principalmente com as árvores plastidiais anteriores (van den Berg et al. 2009 e van den Berg 2014). Também foram recuperadoso subgênero Intermediae, seção Cattleya e Lawrenceanae partem do mesmo ramo e os demais clados em comparação a árvore filogenética de resultados anteriores nas regiões de plastideos.

\section{CONCLUSÃO}

O presente estudo utilizou um conjunto de dados para inferir a filogenia das espécies do grupo do subgênero Cattleya, com ênfase na totalidade das espécies da seção Cattleya. Foi incluída no momento apenas uma região plastidial, e como esta ainda apresenta baixa variação nucleotídica, os suportes foram bastante baixos. Entretanto alguns clados foram reconhecidos e fortemente sustentados. A análise de inferência bayesiana confirmou as relações filogenéticas existentes entre as espécies dentro dos quatro clados: clado A (Catlleya), clado B (Intermedia), clado C (Crispae) e clado D (Lawrenceanae). De modo geral, os clados encontrados abarcaram espécies consideradas 
nas diversas classificações como espécies próximas (Rolfe, 1895, Cogniaux, 1898; Pabst \& Dungs 1975; Fowlie, 1977; Withner, 1988), principalmente em relação as espécies que compõe o clado B. Porem sempre houve falta de consenso entre os autores na classificação das espécies que compões o clado B. Muitas dessas espécies são morfologicamente similares e de difícil distinção, o que também pode explicar a baixa variação encontrada. Para o clado A, mostrou nós com suporte baixos de bootstrap. Os resultados desse estudo para estes clados apresentaram baixa resolução e não esclareceu completamente as relações entre algumas espécies, umas vez que sua taxa de PB foram $<0,9$ em maior parte. Entretando as seção Lawrenceana e Crispae e espécies isoladas da seção Cattleya obtiveram taxas acima $>0,9$ comprovando uma relação bem estabelecida nos dados.(TABELA1). Os resultados sugerem que as populações ocorrentes da seção Cattleya teriam se distribuído através de migração dos Andes a Venezuela chegando ao Brasil, levando em consideração os processos de dispersão histórica, vindos em sentido ao leste brasileiro. A posição de Cattleya maxima, deve ser melhor investigada levando em conta processos que envolveram reticulação entre linhagens ancestrais de outras espécies do grupo bifoliado e unifoliado. Como supracitado, os resultados aqui apresentados são apenas hipóteses (apesar. de estarem embasadas em características morfológicas, fenológicas.

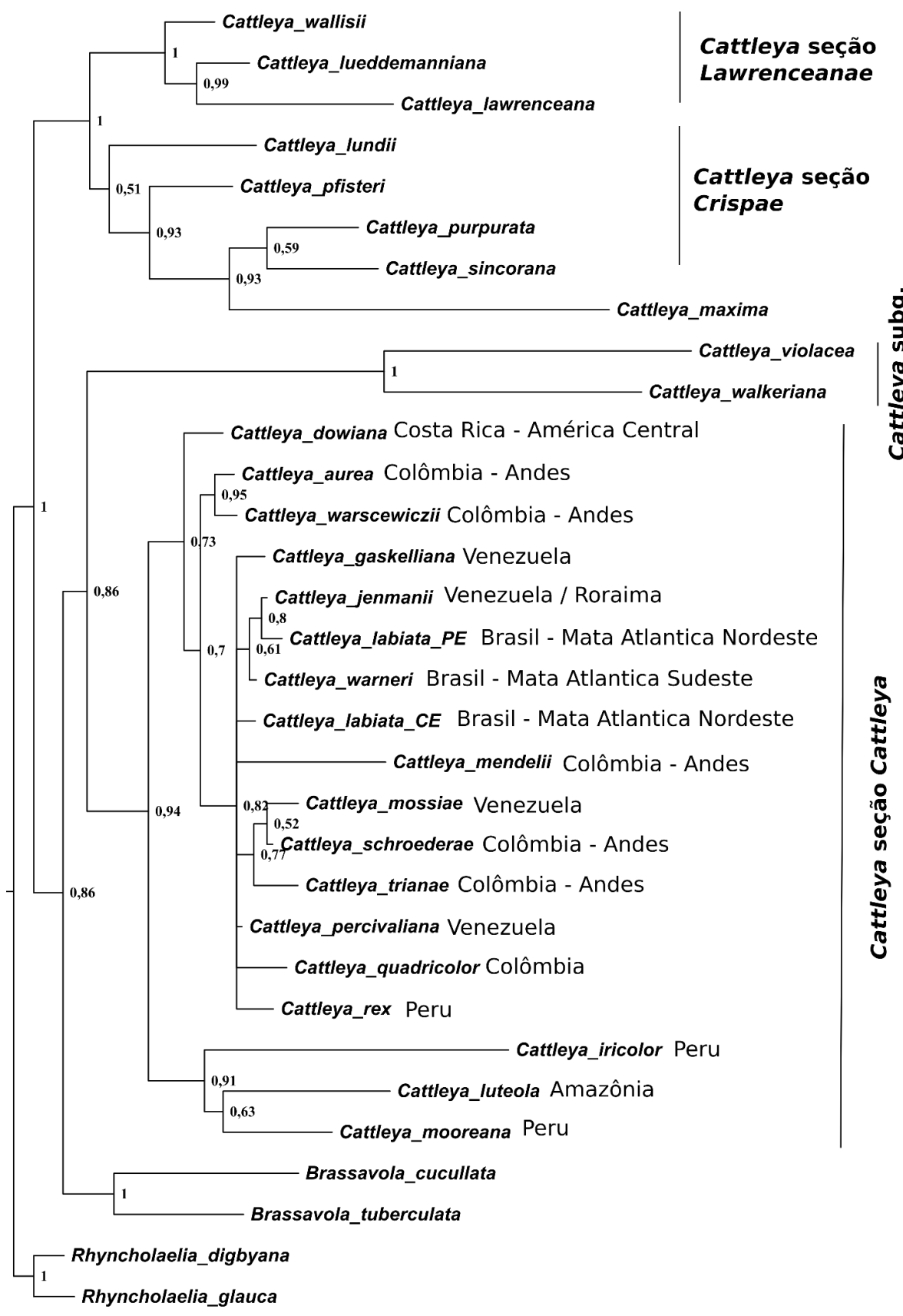

Figura1. Árvore de consenso em maioria das 17.900 árvores resultantes da análise IB, com modelo de evolução particionado na matris :Plastídeo(dados da região

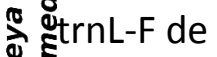
@plastídeos).valores de SPP(em escaal 0-1) gerados no IB. 


\section{REFERÊNCIAS:}

MRMODELTEST. Nylander, J.A.A. (2004) MrModeltest Version 2. Program Distributed by the Author. Evolutionary Biology Centre, Uppsala University, Uppsala.

NIELSEN, L.R. 2000. Natural hybridization between Vanilla claviculata (W. Wright) Sw. and V. barbellata Rchb.f. (Orchidaceae): genetic, morphological, and poliination experimental data. Bot. J. Linean.

Soc.

133 ,

285-302.

PABST, G.F.J., Dungs, F., 1975. Orchidaceae Brasiliensis. Vol. 1. Brucke-Verlag Kurt Schmersow, Hildesheim, Alemanha, $408 p$.

ROLFE, R.A., 1895. Cattleya - What constitutes a species? Orchid Review, 3: 266-270.

SANTOS, T.M. (2011). Eventos antigos de especiação híbrida no grupo bifoliado do gênero Cattleya Lindl. (Orchidaceae) inferidos a partir de uma filogenia baseada em 16 regiões de DNA nuclear e plastidial. Tese de Mestrado, UEFS, 66p.

VAN DEN BERG, C., Higgins, W.E., Dressler, R.L., Whitten, W.M., Soto Arenas, M.A., Culham, A., Chase, M.W., 2000. A phylogenetic analysis of Laeliinae (Orchidaceae) based on sequence data from internal transcribed spacers (ITS) of nuclear ribosomal DNA. Lindleyana 15(2), 96-114.

VAN DEN BERG, C., Chase, M.W., 2000. Nomenclatural notes on Laeliinae - I. Lindleyana 15(2), 115-119.

VAN DEN BERG, C., Goldman, D.H., Freudenstein, J.V., Pridgeon, A.M., Cameron, K.M., Chase, M.W., 2005. An overview of the phylogenetic relationships within Epidendroideae inferred from multiple DNA regions and recircumscription of Epidendreae and Arethuseae (Orchidaceae). Am. J. Bot. 92(4),

VAN DEN BERG, C., Higgins, W.E., Dressler, R.L., Whitten, W.M., Soto-Arenas, M.A. Chase, M.W., 2009. A phylogenetic study of Laeliinae (Orchidaceae) based on combined nuclear and plastid DNA sequences. Ann. Bot. 104 (3), 417-430.

WITHNER, C.L., 1988. The Cattleyas and their relatives. I. The Cattleyas. Timber Press, Portland, Oregon. $147 \mathrm{p}$.

Fowlie, J.A., 1977. The Brazilian bifoliate Cattleyas and their color varieties. Azul Quinta Press, Pomona, California. 132p. 